\title{
CPW-Fed Penta Band Monopole Antenna for Multiservice Wireless Applications
}

\author{
Raj Kumar $^{1,2, *}$, Yedukondalu Kamatham ${ }^{3}$, Samineni Peddakrishna ${ }^{4}$, Ajitha Gaddam ${ }^{5}$ \\ ${ }^{1}$ Department of Electronics and Communication Engineering, Shri Jagdishprasad Jhabarmal Tibrewala University, Rajasthan, India \\ ${ }^{2}$ Department of Electronics and Communication Engineering, Swami Vivekananda Institute of Technology, Secunderabad, India \\ ${ }^{3}$ Department of Electronics and Communication Engineering, CVR College of Engineering, Hyderabad, India \\ ${ }^{4}$ School of Electronics Engineering, VIT-AP University, Amaravati, India \\ ${ }^{5}$ Department of Electronics and Communication Engineering, Institute of Aeronautical Engineering, Hyderabad, India \\ Received 06 September 2021; received in revised form 17 October 2021; accepted 18 October 2021 \\ DOI: https://doi.org/10.46604/aiti.2021.8434
}

\begin{abstract}
A compact triple T-shaped stub with meander loaded strip antenna for penta band applications is proposed. The rectangular patch antenna with meandered and open-ended slot cuts is utilized to realize four operating bands at 2.45 $\mathrm{GHz}, 3.1 \mathrm{GHz}, 5.3 \mathrm{GHz}$, and $6.5 \mathrm{GHz}$ with an impedance bandwidth of $400 \mathrm{MHz}(2.15-2.550 \mathrm{GHz}), 1000 \mathrm{MHz}$ (2.7-3.7 GHz), $200 \mathrm{MHz}(5.4-5.6 \mathrm{GHz})$, and $200 \mathrm{MHz}(6.4-6.6 \mathrm{GHz})$, respectively. For an additional resonance frequency, the length of the central T-shaped stub is slightly modified which causes the variation in the current distribution. As a result, the resonance frequency of $5.5 \mathrm{GHz}$ is divided into two resonance frequency bands which are operating at $5.25 \mathrm{GHz}$ and $5.85 \mathrm{GHz}$ with an impedance bandwidth of $100 \mathrm{MHz}(5.25-5.35 \mathrm{GHz})$ and $200 \mathrm{MHz}$ (5.75-5.95 GHz), respectively. Furthermore, a parametric reflection coefficient and surface current distribution analysis is carried out to understand the strip and slot behavior at resonance frequency bands. Finally, a prototype is fabricated and its reflection coefficient, gain, and radiation pattern are measured. The experimental result shows that the proposed antenna is reliable for penta band applications.
\end{abstract}

Keywords: microstrip antenna, penta band, WLAN, bluetooth, slot, monopole

\section{Introduction}

In recent years, multiband and wideband communication techniques have emerged as viable and efficient communication methods over various multiservice wireless applications. Especially, the progress in the development of compact antennas is playing an extensive role for numerous wideband and multiband applications [1-3]. For developing such antennas, various techniques were being researched in the literature. Among those techniques, multiple slot-based geometry [4] and fractal-shaped geometry [5] have been realized from the conventional patch antenna. However, the fractal-shaped geometry increases its complexity as the number of iterations increases. Therefore, a simple slotted patch antenna becomes an important design element because of its low cost, simple fabrication, low profile, and light weight [6-7].

Nowadays, the planar version of small antennas based on monopole designs has several attractive features, such as the ease of implementation and the ability to integrate with monolithic microwave integrated circuits. Numerous designs have been introduced in the literature for multi-band resonance modes by modifications to the main radiator or in the ground plane element. For instance, the planar double inverted F-antenna [8], printed T monopole [9] with similar resonators, T-shaped monopole having dual L-shaped sleeves on a ground plane [10], and defected ground structure stacked patch [11] antenna for $2.4 \mathrm{GHz}$ and $5.5 \mathrm{GHz}$ wireless local area network (WLAN) applications have been suggested. Alternatively, for triple band applications such as worldwide interoperability for microwave access (WiMAX), WLAN, and long term evolution (LTE)

* Corresponding author. E-mail address: raj_aga_raj@yahoo.co.in 
bands, different structures have been introduced in the literature [12-17]. Xu et al. [13] have proposed an asymmetrical length fork-shaped antenna for 2.45/3.5/5.5 GHz band applications. Pandit and Harish [14] have proposed a trapezoid-shaped monopole with two inverted L-shaped and V-shaped slots for the same application bands. Also, in other research, it has been proposed an equilateral triangular shape with a pair of symmetrical L-shaped parasitic resonator and open-ended slot [15] and an open complementary split-ring resonator (OCSRR) loading antenna [16]. Apart from the above frequency bands, recently it has been proposed a fan-stub-shaped antenna for LTE and WLAN bands [17-18]. In addition, there is little research work on quad band and penta band applications addressed in the literature [19-22]. However, the designs from the work in [19-22] are greater in scale than the one described in this article.

In this manuscript, a compact penta band monopole antenna is considered from the quad band monopole antenna [23] by an additional modification on the open-end rectangular and meandered slots. The design is realized with a coplanar microstrip feeding technique from a basic rectangular monopole patch antenna. Due to rectangular and meandered slots on a patch, it forms like a triple T-shaped resonator which generates an additional resonance frequency at $5.5 \mathrm{GHz}$ and $6.5 \mathrm{GHz}$ respectively. Also, because of the asymmetry introduced in the middle T-shape resonator, the frequency of $5.5 \mathrm{GHz}$ is divided into two resonance frequencies. Hence, the proposed antenna operates on five bands with only $20 \times 18 \mathrm{~mm}^{2}$ overall dimensions. Furthermore, another resonance frequency is generated by making the symmetrical stub resonators asymmetrical, and all these stubs operate as a quarter-wave resonator at their resonance frequency.

\section{Antenna Configuration and Description}

Fig. 1 illustrates a compact coplanar penta band patch antenna with integrated open-ended and meander slots with resonance characteristics and its equivalent circuit representation. As illustrated in Fig. 1(a), two open-ended slots, referred to as rectangular and meandered slots, are cut at different locations on a patch antenna. These perforations are etched to provide three extra resonance frequencies in addition to the initial monopole resonance frequency. Furthermore, another resonance is created by making an asymmetry in the middle portion of the extended strip between two slots (rectangular and meandered) in conjunction with quad band resonance. In this process, all the slot widths are considered uniform. The proposed configuration is planned on the FR-4 substrate (loss tangent of 0.02) and a relative permittivity of 4.4. Both ground plane and microstrip line are etched on the same side of the dielectric with an overall dimension of $20 \times 18 \times 1.6 \mathrm{~mm}^{3}$. All other design parameters and their constitutive dimensions are shown in Fig. 1 as follows: $\mathrm{W}=18, \mathrm{~L}=20, \mathrm{~W}_{1}=16, \mathrm{~W}_{2}=7.5, \mathrm{~W}_{3}=6.5, \mathrm{~W}_{4}=5, \mathrm{~W}_{5}=1, \mathrm{~W}_{6}$ $=7, \mathrm{~W}_{7}=6, \mathrm{~W}_{f}=2, \mathrm{~L}_{1}=7, \mathrm{~L}_{2}=3$, and $\mathrm{L}_{3}=5$. (All dimensions are in mm.) Furthermore, the proposed antenna's equivalent circuit is represented in Fig. 1(b) based on the transmission line theorem, where each metal part acts as an inductance and the gap between two metal parts acts as a capacitance effect.

To realize the design evolution process of penta band resonance, a step-by-step design procedure is shown in Fig. 2. Here, to propose a penta band resonance, a conventional rectangular patch element is chosen as shown in Fig. 2(a). This is considered Antenna \#1 operating with a single resonant frequency. Next, to realize another resonance frequency, an open-ended rectangular slot cut on the topmost of the patch is introduced and denoted as Antenna \#2 (Fig. 2(b)). Because of the patch's slot cut, the current distribution is adjusted, resulting in a new resonance. Next, Antenna \#3 is formed by creating a dual T-shaped and meander stub resonator by etching another slot on Antenna \#2. Due to the inclusion of this slot, the effective electrical length of the patch is extended. As a result, another resonance frequency at $2.45 \mathrm{GHz}$ is produced. Furthermore, the creation of meander construction affects the antenna impedance at $2.65 \mathrm{GHz}$, resulting in notch characteristics. After that, Antenna \#4 (Fig. $2(d)$ ) is created by etching a horizontal strip of length $\mathrm{W}_{4}$, which is extended on Antenna \#3 symmetrically towards the vertical center of the meandering arm. This causes to create another additional resonance in the upper-frequency side. To improve the resonance band even further, the current distribution is controlled on the middle T- shaped resonators. This may be achieved by appropriately modifying the length of the central T-shaped stub resonator, as illustrated in Fig. 2(e). 


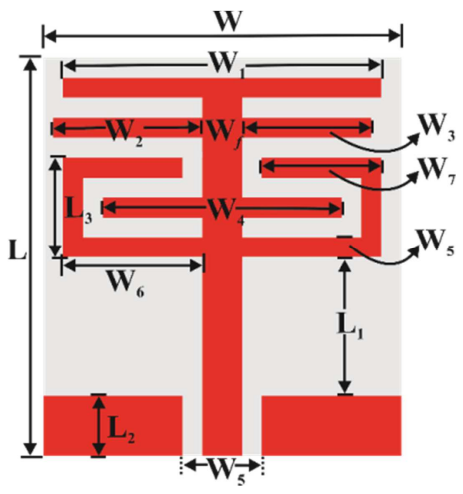

(a) Proposed antenna

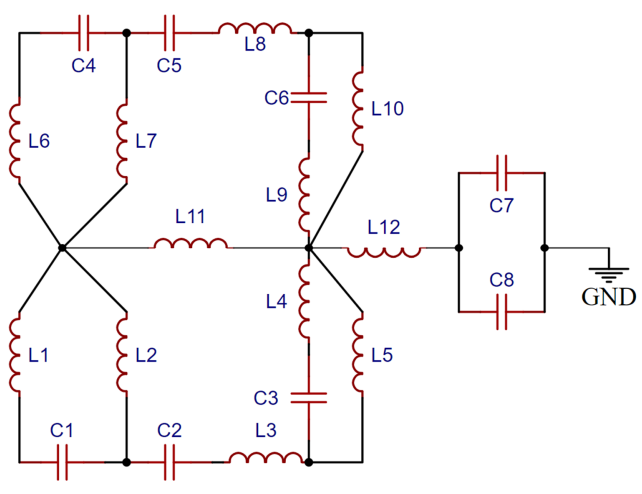

(b) Equivalent circuit representation

Fig. 1 Proposed antenna geometry and its equivalent circuit representation

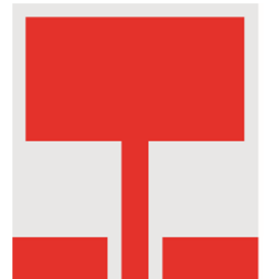

(a) Antenna \#1

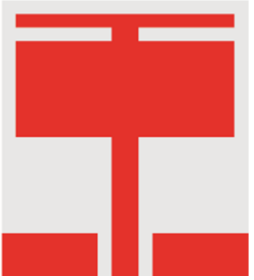

(b) Antenna \#2

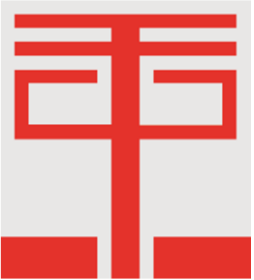

(c) Antenna \#3

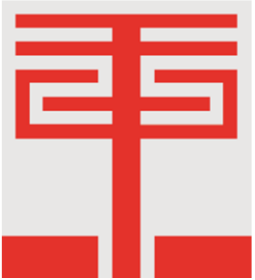

(d) Antenna \#4

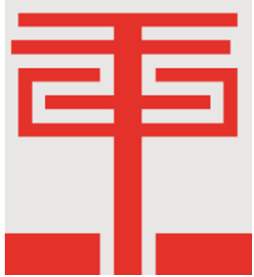

(e) Antenna \#5

Fig. 2 Step-wise design procedure for achieving multiband

\section{Results and Discussion}

Fig. 3 shows a comparison of the simulated reflection coefficients from Antenna \#1 to Antenna \#5. The resonance frequency of Antenna \#1 is observed at $3.0 \mathrm{GHz}$ with a frequency range from $2.3 \mathrm{GHz}$ to $4.0 \mathrm{GHz}$ and an impedance bandwidth (IBW) of $1700 \mathrm{MHz}$. The proposed antenna called Antenna \#5 operates at 2.45 Wi-Fi/Bluetooth band, 3.1 GHz WiMAX band, $5.25 \mathrm{GHz}$ and $5.85 \mathrm{GHz}$ indoor and outdoor WLAN band, and $6.5 \mathrm{GHz}$ mobile/fixed satellite band. The IBWs of this antenna is observed as $450 \mathrm{MHz}, 1050 \mathrm{MHz}, 100 \mathrm{MHz}, 200 \mathrm{MHz}$, and $200 \mathrm{MHz}$ from 2.1-2.55 GHz, 2.75-3.8 GHz, 5.2-5.3 GHz, 5.75-5.95 GHz, and 6.4-6.6 GHz frequency bands respectively. Antenna \#2, Antenna \#3, and Antenna \#4 operates on dual, triple, and quad band resonant frequencies respectively. Antenna \#2 is operating from 2.3-3.9 GHz and 5.2-5.4 GHz bands with an IBW of $1600 \mathrm{MHz}$ and $200 \mathrm{MHz}$ respectively, whereas Antenna \#3 is operating with an IBW of $400 \mathrm{MHz}, 950 \mathrm{MHz}$, and $200 \mathrm{MHz}$ from 2.2-2.6 GHz, 2.85-3.8 GHz, and 5.4-5.6 GHz respectively. The quad band resonance antenna (Antenna \#4) is operating with an IBW of $400 \mathrm{MHz}, 1000 \mathrm{MHz}, 200 \mathrm{MHz}$, and $200 \mathrm{MHz}$ from the operating frequency range 2.15-2.55 GHz, 2.7-3.7 GHz, 5.4-5.6 GHz, and 6.4-6.6 GHz, respectively. Furthermore, the performance comparison among those antennas in terms of IBW, gain, and antenna response is presented in Table 1.

To know more about multiband impedance matching, Antenna \#5 is utilized in a parametric study. Parameters $\mathrm{W}_{2}, \mathrm{~W}_{3}$, and $\mathrm{W}_{4}$ are used to observe Antenna \#5's matching behavior. Fig. 4 depicts the parametric reflection curves concerning a parameter $\mathrm{W}_{2}$ while keeping another parameters constant. The variation of parameter $\mathrm{W}_{2}$ from 7 to 8 mm attains another resonance frequency with a slight variation in the $5.25 \mathrm{GHz}$ and $6.5 \mathrm{GHz}$ resonance frequencies. As the parameter $\mathrm{W}_{2}$ is at 7.5 $\mathrm{mm}$, the attained resonance frequency has high impedance matching at $5.85 \mathrm{GHz}$. Similarly, while keeping other parameters constant, the variation of $\mathrm{W}_{3}$ is analyzed from 7 to $5 \mathrm{~mm}$.

The simulated reflection coefficient curves for various values of the $\mathrm{W}_{3}$ parameter are shown in Fig. 5. As can be observed, there is no resonance between $5.5 \mathrm{GHz}$ and $6.5 \mathrm{GHz}$ frequency in the parameter $\mathrm{W}_{3}$ at $7 \mathrm{~mm}$. The value decreases from 7 to 6.5 $\mathrm{mm}$, another resonance frequency appears with a $0.25 \mathrm{GHz}$ deviation from $5.5 \mathrm{GHz}$ resonance. As the value further decreases from $6.5 \mathrm{~mm}$, the resonance frequency at $6.5 \mathrm{GHz}$ is shifting to a higher frequency side and is going to disappear. Therefore, $6.5 \mathrm{~mm}$ is regarded as the optimal $\mathrm{W}_{3}$ parameter value. 


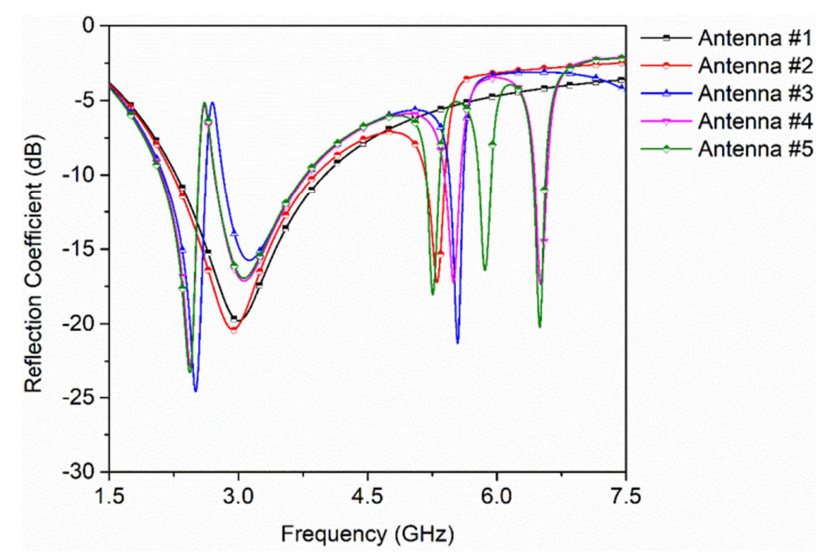

Fig. 3 Comparison of simulated reflection coefficient

Table 1 Comparison of IBW, gain, and antenna response for various antenna configurations

\begin{tabular}{|c|c|c|c|c|}
\hline $\begin{array}{c}\text { Antenna } \\
\text { configuration }\end{array}$ & Antenna subtype & $\begin{array}{l}\text { Resonant frequency } \\
\left(\mathrm{f}_{\mathrm{r}} \mathrm{GHz}\right) / \mathrm{IBW}(\mathrm{MHz})\end{array}$ & $\begin{array}{l}\text { Realized peak gain } \\
\qquad(\mathrm{dB})\end{array}$ & $\begin{array}{l}\text { Antenna } \\
\text { response }\end{array}$ \\
\hline Antenna \#1 & Convectional rectangular patch & $3.0 / 1700$ & -3.0 & Single band \\
\hline Antenna \#2 & Resonator with T-shape patch & $\begin{array}{c}2.7 / 1600 \\
5.3 / 200\end{array}$ & $\begin{array}{l}-2.5 \\
1.4 \\
\end{array}$ & Dual band \\
\hline Antenna \#3 & $\begin{array}{l}\text { Dual T-shaped with } \\
\text { meander strip }\end{array}$ & $\begin{array}{c}2.4 / 400 \\
3.15 / 950 \\
5.5 / 200 \\
\end{array}$ & $\begin{array}{c}-2.5 \\
-2.75 \\
1.35 \\
\end{array}$ & Triple band \\
\hline Antenna \#4 & $\begin{array}{l}\text { Tripple T-shaped } \\
\text { with meander strip }\end{array}$ & $\begin{array}{c}2.45 / 400 \\
3.1 / 1000 \\
5.5 / 200 \\
6.5 / 200 \\
\end{array}$ & $\begin{array}{l}-2.5 \\
-2.8 \\
1.4 \\
1.7 \\
\end{array}$ & Quad band \\
\hline Antenna \#5 & $\begin{array}{l}\text { Asymmetric T-shaped } \\
\text { with meander strip }\end{array}$ & $\begin{array}{c}2.45 / 450 \\
3.1 / 1050 \\
5.25 / 100 \\
5.85 / 200 \\
6.5 / 200\end{array}$ & $\begin{array}{c}-2.5 \\
-2.8 \\
1.05 \\
1.4 \\
1.25\end{array}$ & Penta band \\
\hline
\end{tabular}

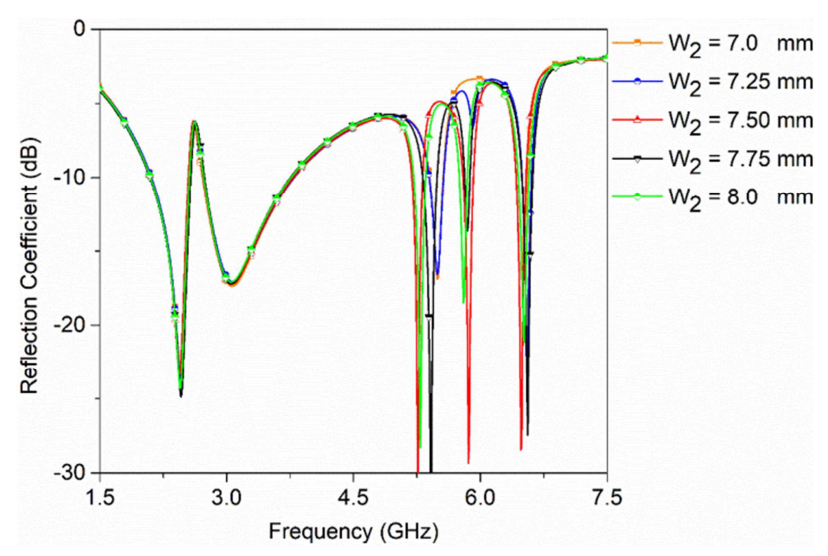

Fig. 4 Reflection coefficient variation with $\mathrm{W}_{2}$

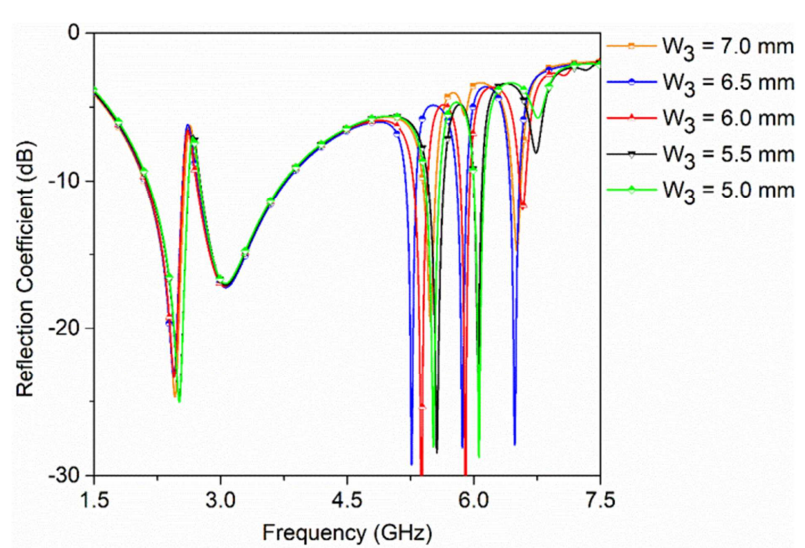

Fig. 5 Reflection coefficient variation with $\mathrm{W}_{3}$

In addition to the variations in $\mathrm{W}_{2}$ and $\mathrm{W}_{3}$, there is also a parametric variation in $\mathrm{W}_{4}$ (decreases from 6 to $0 \mathrm{~mm}$ ) that is performed independently while keeping parameter $\mathrm{W}_{2}$ at $7.5 \mathrm{~mm}$ and $\mathrm{W}_{3}$ at $6.5 \mathrm{~mm}$. The simulated reflection coefficient curves for parameter $\mathrm{W}_{4}$ are shown in Fig. 6. The results show that when the parameter value decreases, it affects upper resonance frequencies. The variation of the upper resonance frequency is shifted to a higher frequency side with the disappearing of resonance frequency at $5.85 \mathrm{GHz}$.

To explore the functionality of Antenna \#5, the simulated real and imaginary input impedance characteristics against frequency are shown in Fig. 7. The resonance property of the antenna can be seen in enclosed circle areas I, II, III, IV, and V, which have about $50 \mathrm{Ohm}$ real and $0 \mathrm{Ohm}$ imaginary components of input impedance and generate resonant modes at around $2.45,3.1,5.25,5.85$, and $6.5 \mathrm{GHz}$, respectively. 
To further investigate the resonance behavior, the current distribution at various frequencies with various antenna designs of Fig. 2 is analyzed in Fig. 8. The current distribution of Antenna \#1 is observed in a forward direction from a feed line and bottom edge of the patch. Next, to understand the effect of the open-ended slot on Antenna \#2, the surface current distribution is analyzed in upper resonance frequency. From this analysis, it is observed that most of the current distribution is concentrated on the upper T-shaped stub resonator. This implies the resonance at $5.3 \mathrm{GHz}$ is caused due to upper T-shaped resonator.

For further analysis of resonance bands, the surface current distribution of Antenna \#3 is analyzed in lower resonance frequency. From Antenna \#3, the current distribution at $2.4 \mathrm{GHz}$ is observed on the vertical strip in the forward direction. Furthermore, it is observed that this resonance is created due to the removal of some frequencies around $2.65 \mathrm{GHz}$. Additionally, the current distribution at $6.5 \mathrm{GHz}$ is analyzed after adding the third horizontal strip on Antenna \#3 and it is called Antenna \#4. The observed current is concentrated around the newly added strip.

Finally, to understand the resonance behavior due to asymmetry, the current distribution of Antenna \#5 at $5.25 \mathrm{GHz}$ and $5.85 \mathrm{GHz}$ are analyzed. From the current distribution at $5.25 \mathrm{GHz}$, the current is mostly concentrating on the upper left side of the stub resonator and at $5.85 \mathrm{GHz}$ concentrating mostly on the upper right side of the stub resonator. Also, there is a slight current concentration on the middle arm. This is because of the coupling effect between $5.85 \mathrm{GHz}$ and $6.5 \mathrm{GHz}$ frequencies.

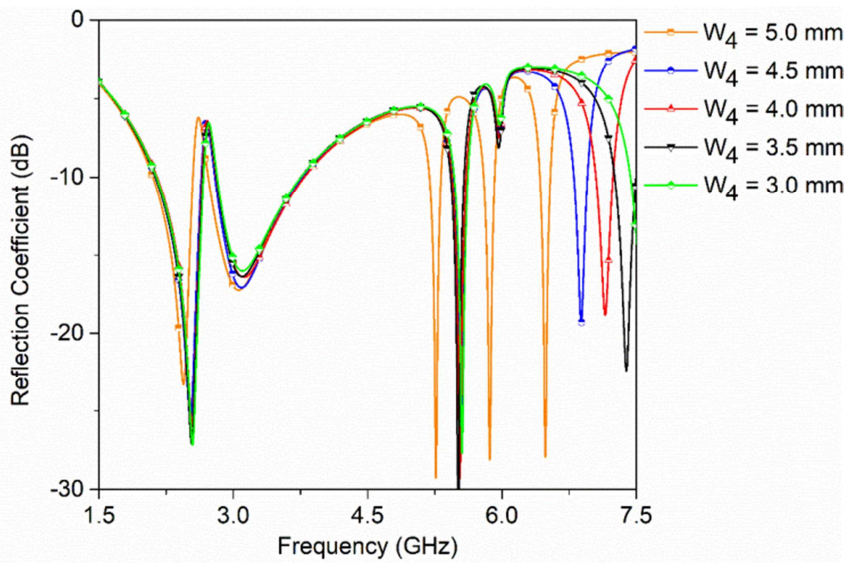

Fig. 6 Reflection coefficient variation with $\mathrm{W}_{4}$

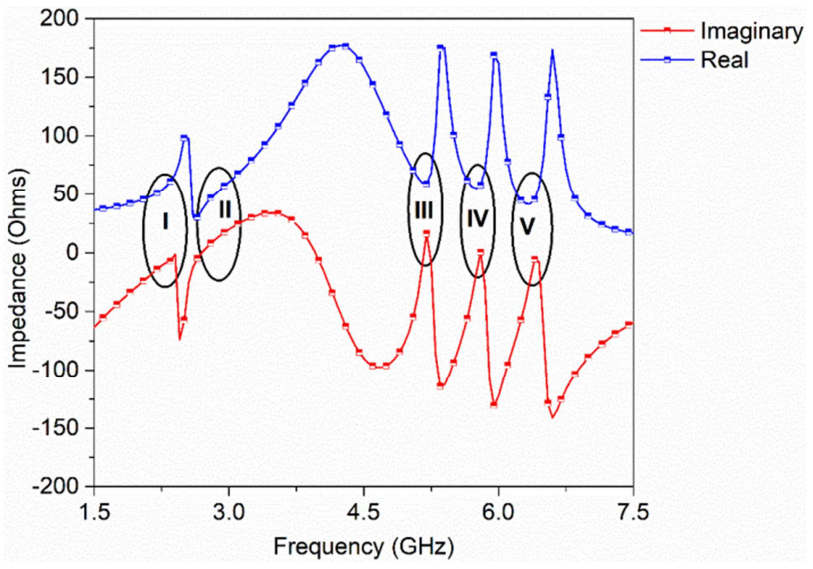

Fig. 7 Impedance variation against the frequency of Antenna \#5

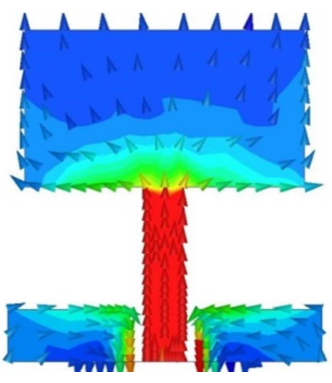

(a) Antenna \#1 at $3 \mathrm{GHz}$

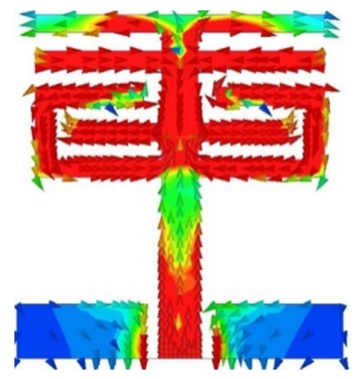

(d) Antenna \#4 at $6.5 \mathrm{GHz}$

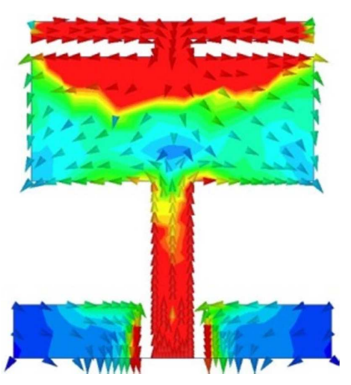

(b) Antenna \#2 at $5.5 \mathrm{GHz}$

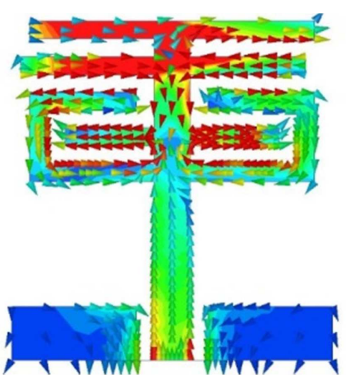

(e) Antenna \#5 at $5.25 \mathrm{GHz}$

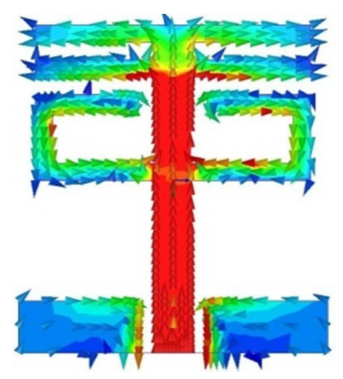

(c) Antenna \#3 at $2.4 \mathrm{GHz}$

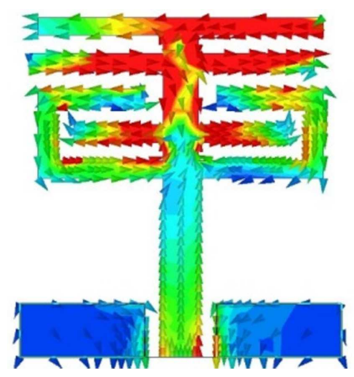

(f) Antenna \#5 at $5.85 \mathrm{GHz}$

Fig. 8 Current distribution of Antenna \#1 to Antenna \#5 at different resonance frequency 
Based on the modified circuit current distribution from a rectangular monopole, the achieved additional resonance frequencies at $2.4 \mathrm{GHz}, 5.25 \mathrm{GHz}, 5.85 \mathrm{GHz}$, and $6.5 \mathrm{GHz}$ are obtained from Eqs. (1)-(4). From Eq. (1), the calculated resonance frequency is $2.53 \mathrm{GHz}$ at $\lambda=72 \mathrm{~mm}$, while the simulated frequency is $2.45 \mathrm{GHz}$. Similarly, from Eqs. (2)-(4), the calculated resonance frequencies are $5.37 \mathrm{GHz}, 6 \mathrm{GHz}$, and $7 \mathrm{GHz}$ at $34 \mathrm{~mm}, 30 \mathrm{~mm}$, and $24 \mathrm{~mm}$ wavelength, respectively. It is observed from the calculation, the predicted values are close to simulated results, except at $6.5 \mathrm{GHz}$. This deviation may be due to the presence of additional coupling gap capacitance from the meandering strip.

$$
\begin{aligned}
& \text { At } f=2.45 \mathrm{GHz}, \frac{\lambda}{4}=\frac{c}{4 \sqrt{\varepsilon_{\text {reff }} f}} \simeq L+W_{f}-L_{2}-1 \approx 18 \\
& \text { At } f=5.25 \mathrm{GHz}, \frac{\lambda}{4}=\frac{c}{4 \sqrt{\varepsilon_{\text {reff }} f}} \simeq W_{2}+W_{5} \approx 8.5 a \\
& \text { At } f=5.85 \mathrm{GHz}, \frac{\lambda}{4}=\frac{c}{4 \sqrt{\varepsilon_{\text {reff }}} f} \simeq W_{3}+W_{5} \approx 7.5 \\
& \text { At } f=6.5 \mathrm{GHz}, \frac{\lambda}{4}=\frac{c}{4 \sqrt{\varepsilon_{\text {reff }} f}} \simeq W_{4}+W_{5} \approx 6
\end{aligned}
$$

where

$$
\varepsilon_{\text {reff }}=\frac{\mathcal{\varepsilon}_{r}+1}{2}
$$

To describe the efficient communication between transmitter and receiver made by the proposed antenna, another important parameter called radiation efficiency is plotted in Fig. 9. Radiation efficiency defines how much power is radiated from the received input power. In the proposed design, the radiation efficiency of Antenna \#4 and Antenna \#5 is observed between $97 \%$ and $65 \%$ in the operating band. Also, it is observed in the non-operating band a very low efficiency in the frequency range of interest.

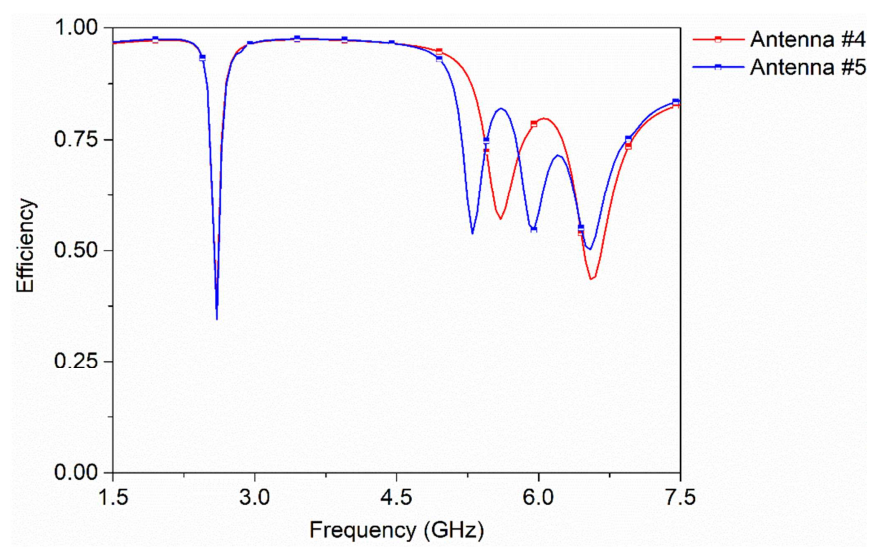

Fig. 9 Radiation efficiency variation against frequency

\section{Experimental Validation}

To confirm the simulated results, the designed antenna prototypes such as Antenna \#4 and Antenna \#5 are fabricated and validated using a vector network analyzer and anechoic chamber setup. Fig. 10 shows the photographs of the fabricated prototypes, reflection coefficient, and pattern measurement setup. Fig. 11 indicates the reflection coefficient performance of the two antennas. The reflection coefficient is measured using Anritsu MS2037C VNA after doing the calibration in the 
frequency range setup. With slight variations, a close agreement between the simulated and the measured results are achieved. The observed reflection coefficient of Antenna \#5 is found at 2.15-2.55 GHz, 2.7-3.6 GHz, 5.2-5.35 GHz, 5.7-6.0 GHz, and 6.4-6.65 GHz resonant bands with an IBW of $400 \mathrm{MHz}, 900 \mathrm{MHz}, 150 \mathrm{MHz}, 300 \mathrm{MHz}$, and $250 \mathrm{MHz}$ respectively. The deviation between the validated and simulated results below $-10 \mathrm{~dB}$ is observed at their matching bands, which are $50 \mathrm{MHz}$, $150 \mathrm{MHz}, 50 \mathrm{MHz}, 100 \mathrm{MHz}$, and $50 \mathrm{MHz}$ from lower resonance to upper resonance, respectively. Furthermore, the achieved bandwidth parameters meet the requirement of Bluetooth, WiMAX, WLAN, fixed satellite/mobile communication specifications. As a result, the proposed antenna meets the requirement of multiband applications.

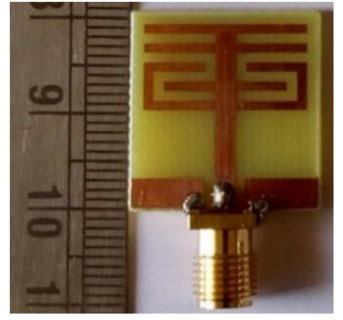

(a) Antenna \#4 prototype

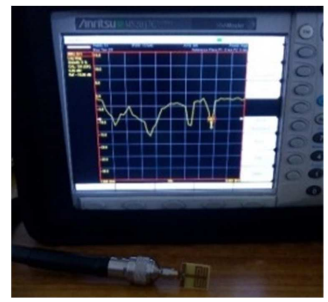

(c) Antenna \#4 $\mathrm{S}_{11}$ measurement setup

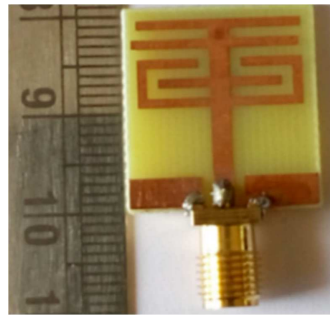

(b) Antenna \#5 prototype

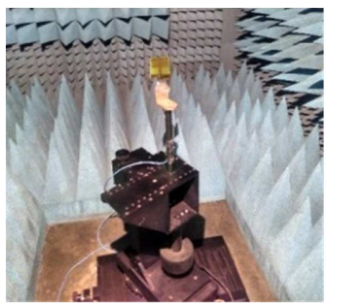

(d) Antenna \#5 pattern measurement setup

Fig. 10 Fabricated prototypes and measurement setups for the validation

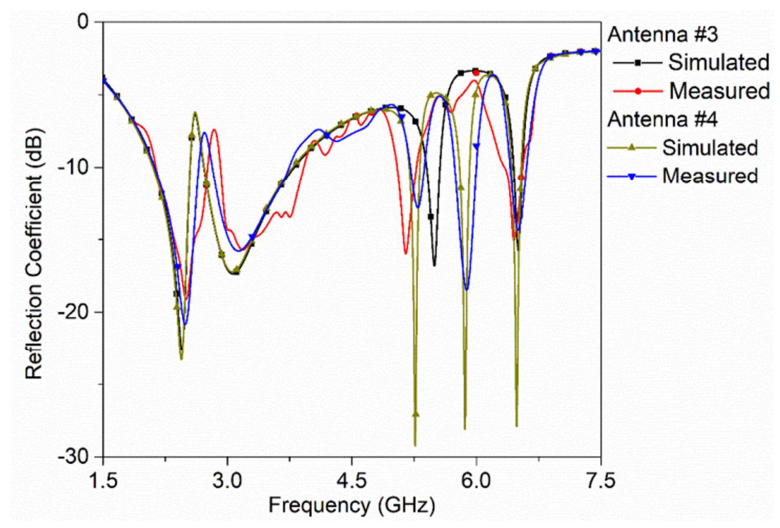

Fig. 11 Comparison of reflection coefficient for the proposed antenna

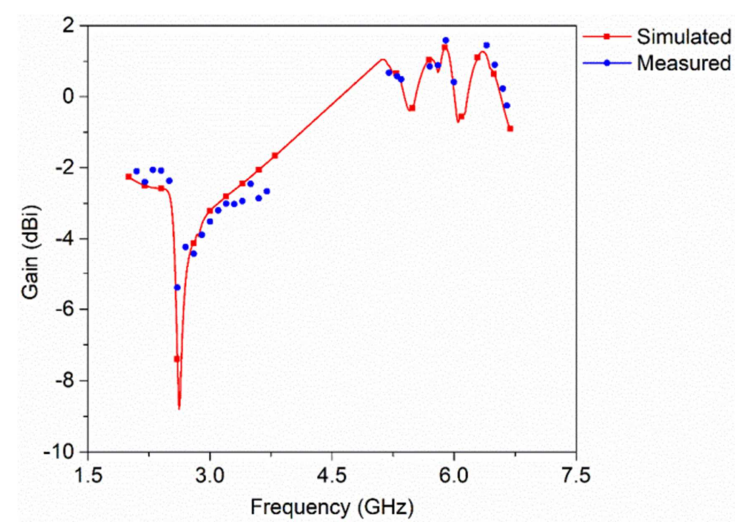

Fig. 12 Realized gain comparison of Antenna \#4

In an anechoic chamber, the gain is measured using the two-antenna method. The measurement is carried out at some discrete frequencies in the matched frequency region. The gain comparison of the proposed antenna is shown in Fig. 12. The simulated peak comprehended gain from 2.1-2.6 GHz, 2.7-3.7 GHz, 5.2-5.3 GHz, 5.75-5.95 GHz, and 6.4-6.6 GHz bands are $-2.4 \mathrm{dBi},-1.8 \mathrm{dBi}, 1.05 \mathrm{dBi}, 1.4 \mathrm{dBi}$, and $1.25 \mathrm{dBi}$ respectively, whereas the measured gain from 2.1-2.7 GHz, 2.8-3.7 GHz, 5.2-5.35 GHz, 5.7-6.0 GHz, and 6.4-6.65 GHz bands are 0-2.05 dBi, -2.45 dBi, 0.65 dBi, $1.6 \mathrm{dBi}$, and $1.45 \mathrm{dBi}$ respectively.

Fig. 13 shows the simulated and measured radiation pattern comparison of both co- and cross-polarization. Measurements are carried out between two antennas, one of which is a high gain horn antenna and the other is a fabricated prototype. To measure the pattern of the proposed antenna, two principle planes in both the elevation plane (E-plane or XOZ plane) and azimuth plane (H-plane or YOZ plane) are considered. The measurements are taken at various frequencies including 2.45, 3.1, 5.25, 5.85, and 6.5 GHz. In the H-plane, the proposed antenna has almost omnidirectional radiation patterns, while in the E-plane, it exhibits dipole-like radiation patterns. It is also observed that there is a considerable comparison between co- and 
cross-polarization in E-plane at higher frequencies. Additionally, to show the advantage of the proposed device, a comparison of the reported multi-band antennas in the literature is given in Table 2. It can be seen that the proposed antenna is compared in terms of the dimensions, the operating antenna response, and the corresponding bandwidths with various application bands. From the table, it can be easily recognized that the proposed antenna is more compact than the ones in the existing literature with five resonance band frequencies.
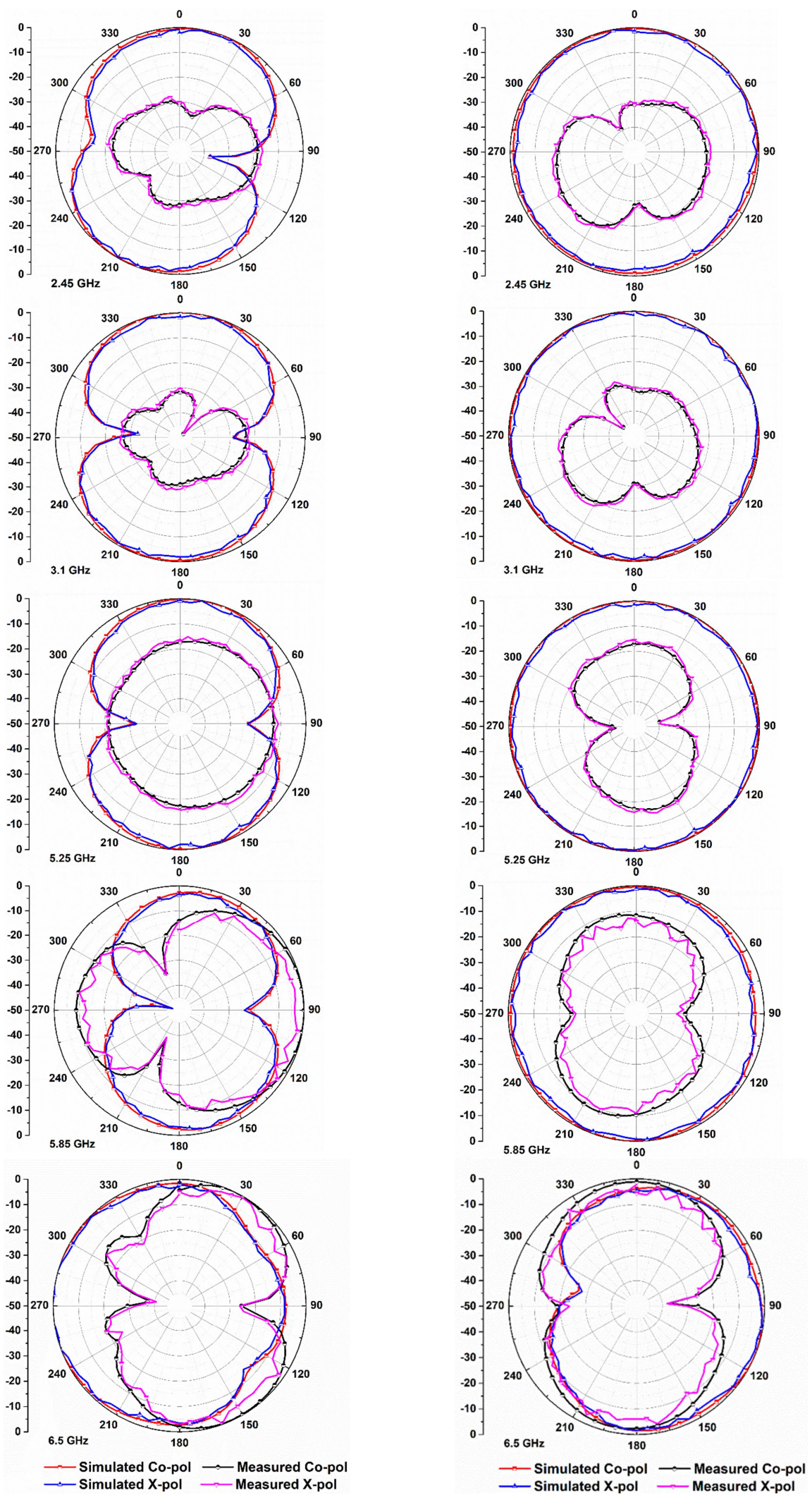

(a) E-plane

(b) H-plane

Fig. 13 The simulated and measured radiation patterns of the antenna 
Table 2 Comparison of the penta band antennas in the existing literature

\begin{tabular}{|c|c|c|c|c|c|}
\hline Ref. & $\begin{array}{c}\text { Size } \\
\left(\mathrm{W} \times \mathrm{L} \times \mathrm{H} \mathrm{mm}^{3}\right)\end{array}$ & $\begin{array}{l}\text { Ground size } \\
\quad\left(\mathrm{mm}^{2}\right)\end{array}$ & $\begin{array}{l}\text { Antenna } \\
\text { response }\end{array}$ & $\begin{array}{c}\mathrm{f}_{\mathrm{r} 1 / \mathrm{r} 2 / \mathrm{r} 3 / \mathrm{r} 4 / \mathrm{r} 5} \\
(\mathrm{GHz})\end{array}$ & $\begin{array}{c}\text { IBWs/BWs } \\
(\mathrm{GHz})\end{array}$ \\
\hline$[9]$ & $75 \times 75 \times 0.8$ & $75 \times 50$ & Dual band & $2.4 / 5.2$ & $\begin{array}{l}2.4-2.484 \\
5.15-5.35\end{array}$ \\
\hline$[10]$ & $40 \times 68 \times 0.8$ & $40 \times 55$ & Dual band & $2.4 / 5.8$ & $\begin{array}{l}1.76-2.79 \\
5.19-5.51\end{array}$ \\
\hline$[11]$ & $22 \times 18.5 \times 1.6$ & $22 \times 18.5$ & Dual band & $2.45 / 5.1$ & $\begin{array}{l}2.31-2.78 \\
4.87-5.74\end{array}$ \\
\hline$[12]$ & $25 \times 25 \times 0.8$ & $25 \times 10$ & Dual band & $3.5 / 5.5$ & $\begin{array}{l}3.4-3.6 \\
5.6-5.8\end{array}$ \\
\hline$[13]$ & $20 \times 37 \times 0.508$ & $20 \times 10.7$ & Triple band & $2.4 / 5.2 / 5.8$ & $\begin{array}{c}2.4-2.65 \\
3.3-4.05 \\
5-5.98\end{array}$ \\
\hline$[14]$ & $21 \times 24 \times 0.8$ & $21 \times 7.3$ & Triple band & $2.4 / 5.2 / 5.8$ & $\begin{array}{c}2.35-2.53 \\
3.2-4.56 \\
5.24-6.06\end{array}$ \\
\hline$[15]$ & $36 \times 40 \times 1.52$ & $36 \times 14.4$ & Triple band & $2.4 / 3.5 / 5.8$ & $\begin{array}{l}2.20-2.65 \\
3.47-3.55 \\
5.75-5.83\end{array}$ \\
\hline$[16]$ & $30 \times 40 \times 0.8$ & $9.7 \times 17.35$ & Triple band & $2.6 / 3.4 / 5$ & $\begin{array}{c}2.40-2.70 \\
3.32-4.00 \\
4.76-5.8 \\
\end{array}$ \\
\hline$[17]$ & $24 \times 30 \times 0.79$ & $24 \times 5$ & Triple band & $2.5 / 3.5 / 5.5$ & $\begin{array}{l}2.50-2.71 \\
3.37-3.63 \\
5.20-5.85\end{array}$ \\
\hline$[19]$ & $28 \times 38 \times 1.6$ & $28 \times 11$ & Quad band & $2.47 / 3.2 / 5.39 / 8.87$ & $\begin{array}{l}2.44-2.55 \\
2.89-3.80 \\
5.18-5.66 \\
8.28-9.90\end{array}$ \\
\hline$[20]$ & $57.37 \times 67.5 \times 1.6$ & $67.5 \times 30$ & Quad band & $1.2 / 1.65 / 2.4 / 3.5$ & $\begin{array}{c}1.15-1.25 \\
1.5-1.9 \\
2.39-2.49 \\
3.5\end{array}$ \\
\hline$[21]$ & $24 \times 32 \times 1.6$ & $24 \times 13.5$ & Quad band & $2.45 / 3.5 / 5.2 / 5.8$ & $\begin{array}{l}2.31-2.58 \\
3.16-3.57 \\
5.11-5.23 \\
5.72-5.92 \\
\end{array}$ \\
\hline$[22]$ & $50 \times 50 \times 1.6$ & $50 \times 25$ & Penta band & $1.81 / 2.22 / 2.51 / 2.85 / 3.08$ & $\begin{array}{l}4.97 \\
2.70 \\
5.98 \\
8.42 \\
2.92\end{array}$ \\
\hline $\begin{array}{l}\text { This } \\
\text { work }\end{array}$ & $20 \times 18 \times 1.6$ & $18 \times 3$ & Penta band & $2.45 / 3.1 / 5.25 / 5.85 / 6.5$ & $\begin{array}{c}2.1-2.55 \\
2.75-3.8 \\
5.2-5.3 \\
5.75-5.95 \\
6.4-6.6\end{array}$ \\
\hline
\end{tabular}

\section{Conclusions}

In this article, a simple penta band antenna is designed and validated from the fabricated prototype. By cutting open-ended and meandering slots in a radiator in a systematic way, five resonance bands are generated. Because of cutting open-ended and meandering slots, T-shaped stub resonators are formed. Parametric studies are performed to show the influence of those stubs on antenna performance. With an acceptable gain and a consistent radiation pattern, the suggested antenna can encompass Wi-Fi/Bluetooth, WiMAX, WLAN, and fixed satellite operating bands. Finally, the antenna parameters are measured and validated with the fabricated prototype. In addition, the proposed antenna is compact compared to current penta band antennas with an overall dimension of $20 \times 18 \times 1.6 \mathrm{~mm}^{3}$, which has the benefit of being easier to be included in printed circuit boards (PCBs). Hence, this antenna can be used in multiband wireless communications applications such as $5 \mathrm{G}$ and beyond. 


\section{Conflicts of Interest}

The authors declare no conflict of interest.

\section{References}

[1] J. F. Huang, M. T. Wu, and J. Y. Wen, "A Compact Triple-Band Antenna Design for UMTS WLAN and WiMAX Applications," Microwave and Optical Technology Letters, vol. 51, no. 9, pp. 2207-2212, September 2009.

[2] H. W. Liu and C. H. Ku, "Novel Planar Triple-Band Monopole Antenna for WiMAX/WLAN Applications," Microwave and Optical Technology Letters, vol. 52, no. 11, pp. 2405-2408, November 2010.

[3] V. Kollipara, S. Peddakrishna, and J. Kumar, "Planar EBG Loaded UWB Monopole Antenna with Triple Notch Characteristics," International Journal of Engineering and Technology Innovation, vol. 11, no. 4, pp. 294-304, September 2021.

[4] S. Patil, V. Kapse, S. Sharma, and A. K. Pandey, "Low Profile Wideband Dual-Ring Slot Antenna for Biomedical Applications," Proceedings of Engineering and Technology Innovation, vol. 19, pp. 38-44, August 2021.

[5] A. Kumar and A. P. S. Pharwaha, "Design and Optimization of Micro-Machined Sierpinski Carpet Fractal Antenna Using Ant Lion Optimization," International Journal of Engineering and Technology Innovation, vol. 10, no. 4, pp. 306-318, September 2020.

[6] R. Kumar and Y. Kamatham, "Compact Tri-Band Monopole Antenna for 2.4/5.8 GHz WLAN and 8.3 GHz ITU-T Applications," IEEE International Conference on Electrical, Computer, and Communication Technologies, pp. 1-4, October 2019.

[7] U. Chakraborty, S. Chatterjee, S. K. Chowdhury, and P. P. Sarkar, "A Compact Microstrip Patch Antenna for Wireless Communication," Progress in Electromagnetics Research C, vol. 18, pp. 211-220, April 2012.

[8] Y. L. Kuo, Y. T. Cheng, and K. L. Wong, "Printed Inverted-F Antennas for Applications in Wireless Communication," IEEE Antennas and Propagation Society International Symposium, pp. 454-457, June 2002.

[9] Y. L. Kuo and K. L. Wong, "Printed Double-T Monopole Antenna for 2.4/5.2 GHz Dual-Band WLAN Operations," IEEE Transactions on Antennas and Propagation, vol. 51, no. 9, pp. 2187-2192, November 2003.

[10] J. W. Wu, H. M. Hsiao, J. H. Lu, and Y. D. Wang, "Dual-Broadband T-Shaped Monopole Antenna for Wireless Communication,” IEEE Antennas and Propagation Society International Symp., pp. 470-473, July 2005.

[11] M. K. Khandelwal, B. Kanaujia, S. Dwari, S. Kumar, and A. K. Gautam, "Analysis and Design of Dual-Band Compact Stacked Microstrip Patch Antenna with Defected Ground Structure for WLAN/WiMAX Applications," International Journal of Electronics and Communications, vol. 69, no. 1, pp. 39-47, January 2015.

[12] H. Li, L. Kang, D. W. Mi, and Y. Z. Yin, "Simple Dual Band-Notched UWB Antenna Loaded with Single U-Shaped Resonator," Microwave and Optical Technology Letters, vol. 57, no. 9, pp. 2129-2134, September 2015.

[13] L. Xu, Z. Y. Xin, and J. He, "A Compact Triple-Band Fork-Shaped Antenna for WLAN/WiMAX Applications," Progress in Electromagnetics Research Letters, vol. 40, pp. 61-69, January 2013.

[14] V. K. Pandit and A. R. Harish, "A Compact CPW-Fed Triple-Band Monopole Antenna for WLAN/WiMAX Applications," Asia-Pacific Microwave Conference, pp. 1-4, December 2016.

[15] L. Chouti, I. Messaoudene, T. A. Denidni, and A. Benghalia, "Triple-Band CPW-Fed Monopole Antenna for WLAN/WiMAX Applications,” Progress in Electromagnetics Research Letters, vol. 69, pp. 1-7, June 2017.

[16] R. Pandeeswari and S. Raghavan, "A CPW Fed Triple-Band OCSRR Embedded Monopole Antenna with Modified Ground for WLAN and WiMAX Applications," Microwave and Optical Technology Letters, vol. 57, no. 10, pp. 2413-2418, October 2015.

[17] A. Kumar, D. Jhanwar, and M. M. Sharma, "A Compact Printed Multistubs Loaded Resonator Rectangular Monopole Antenna Design for Multiband Wireless System," International Journal of RF and Microwave Computer-Aided Engineering, vol. 27, no. 9, e21147, November 2017.

[18] K. A. Khan and S. M. Nokerov, "Optimization of Multi-Band Characteristics in Fan-Stub Shaped Patch Antenna for LTE (CBRS) and WLAN Bands," Proceedings of Engineering and Technology Innovation, vol. 18, pp. 25-35, April 2021.

[19] N. Kumawat, S. Gurjar, and Sunita, "A Compact Triple and Quadruple Band Antenna for Bluetooth/WiMAX/WLAN/ X-Band Applications," Proceedings of International Conference on ICT for Sustainable Development, pp. 1-10, July 2015.

[20] K. Yu, Y. Li, and X. Luo, "A CPW-Fed Quad-Band Monopole Antenna for L-Band, WLAN and WiMAX Communication Applications,” IEEE Progress in Electromagnetic Research Symp., pp. 1-5, August 2016. 
[21] A. Khan, S. I. Naqvi, F. Arshad, Y. Amin, and H. Tenhunen, “A Compact Quad-Band CPW-Fed Planar Resonator for Multiple Wireless Communication Applications,” Applied Computational Electromagnetics Society Journal, vol. 32, no. 11, pp. 1001-1007, December 2017.

[22] D. Sarkar, K. Saurav, K. V. Srivastava, and S. Awasthi, “A Compact Penta-Band CPW-Fed Monopole Antenna Using LC Resonator and Interdigital Capacitor,” IEEE Applied Electromagnetics Conference, pp. 18-21, December 2015.

[23] R. Kumar and Y. Kamatham, "Design of Compact Quad Band Monopole Antenna Using Open-Ended and Meandered Slot," International Conference on Innovations in Electrical and Electronics Engineering, pp. 627-634, January 2021.

Copyright $@$ by the authors. Licensee TAETI, Taiwan. This article is an open access article distributed under the terms and conditions of the Creative Commons Attribution (CC BY-NC) license (https://creativecommons.org/licenses/by-nc/4.0/). 